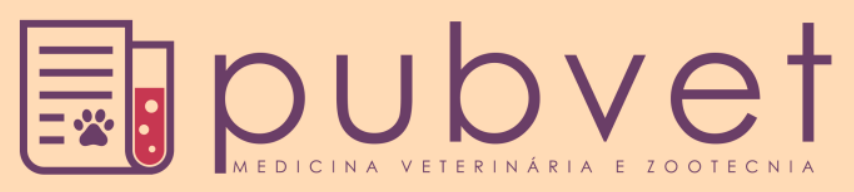

HTTP://DX.DOI.ORG/10.22256/PUBVET.VI1N5.466-469

\title{
Hipovitaminose A em tigre d'água (Trachemys dorbignyi): Relato de caso
}

\author{
Mariene Galvão Pereira ${ }^{1 *}$, Bruno Ferreira Carneiro ${ }^{2}$, Marina Mendonça de Miranda ${ }^{3}$, \\ Luciana Batalha de Miranda Araújo ${ }^{4}$
}

${ }^{1}$ Médica Veterinária. Goiânia-GO, Brasil.E-mail: mariene_gp@hotmail.com

${ }^{2}$ Médico Veterinário Especialista da Clínica Refúgio Silvestre e Mestre pela Universidade Federal de Goiás. Goiânia-GO, Brasil.E-mail: brunofcvet@hotmail.com

${ }^{3}$ Médica Veterinária Especialista da Clínica Refúgio Silvestre. Goiânia-GO, Brasil. E-mail: contato@ refugiosilvestre.com.br

${ }^{4}$ Docente da Universidade Federal de Goiás, Departamento de Medicina Veterinária Preventiva. Goiânia-GO, Brasil. E-mail: batalha@ufg.br

*Autor para correspondência

RESUMO. A hipovitaminose A é um desequilíbrio nutricional que ocorre em diversas classes animais, uma delas é a dos répteis devido ao erro de manejo alimentar. $\mathrm{O}$ betacaroteno é um carotenoide, o precursor mais importante da vitamina A e é encontrado em vegetais. Os répteis não absorvem bem o betacaroteno, por isso ele deve ser um componente da dieta. A vitamina A tem o papel importantíssimo de manter o tecido epitelial de todo organismo. Os sinais clínicos decorrentes desse desequilíbrio nutricional em testudíneos são: metaplasia escamosa, hiperqueratose dos epitélios respiratório e ocular, abscesso aural, blefaroedema, descamação da carapaça. O diagnóstico é feito basicamente através dos sinais clínicos, histórico alimentar e responsividade ao tratamento. $\mathrm{O}$ tratamento instituído é a aplicação de doses elevadas de vitamina A, juntamente com manejo nutricional adequado. $\mathrm{O}$ presente relato descreve o caso de um tigre d'água (Trachemys dorbignyi), de 23 anos de idade, atendido na Clínica Veterinária Refúgio Silvestre em Goiânia, apresentando blefaroedema, descamação de carapaça, ataxia, incoordenação motora, letargia, dificuldade de locomoção. Após todo um protocolo terapêutico instituído, o animal não respondeu ao tratamento e veio à óbito depois de 11 dias de internação. Este relato de caso tem como objetivo mostrar a importância dos manejos nutricional e ambiental na qualidade de vida dos pets silvestres e exóticos.

Palavras chave: animais silvestres, deficiência de vitaminas, alimentação réptil

\section{Hypovitaminosis in Trachemys dorbignyi: Case report}

ABSTRACT. Hypovitaminosis A is a nutritional imbalance that occurs in several animal classes, one of which is reptile due to food management error. Beta carotene is a carotenoid, the most important precursor of vitamin A and is found in vegetables. Reptiles do not absorb beta carotene well, so it should be a component of the diet. Vitamin A plays the very important role of maintaining the epithelial tissue of every organism. The clinical signs resulting from this nutritional imbalance in testudines are: squamous metaplasia, hyperkeratosis of the respiratory and ocular epithelia, aural abscess, blepharoedema, peeling of the carapace. The diagnosis is made basically through clinical signs, food history and treatment responsiveness. The treatment instituted is the application of high doses of vitamin A along with adequate nutritional management. This present report describes the case of turtle Trachemys dorbignyi of 23-year-old, attended at the Silvestre Veterinary Clinic in Goiânia, presenting blepharoedema, carapace desquamation, ataxia, motor incoordination, lethargy, difficulty in locomotion. After an established therapeutic protocol, the animal did not respond to the treatment and died after 11 days of 
hospitalization. This case report aims to show the importance of nutritional and environmental management in the quality of life of wild and exotic pets.

Keywords: wildlife, vitamin deficiency, feeding of reptile

\section{Deficiencia de vitamina A en Trachemys dorbignyi: Reporte de un caso}

RESUMEN. La deficiencia de vitamina A es un desequilibrio nutricional que ocurre en diferentes clases de animales, entre ellas los reptiles por causa del mal manejo de la alimentación. El beta caroteno es un carotenoide, el precursor más importante de la vitamina A y se encuentra en los vegetales. Los reptiles no absorben bien el beta-caroteno, por eso este debe ser un componente de la dieta. La vitamina A tiene la importante función de mantener el tejido epitelial del todo el organismo. Los signos clínicos que resultan de este desequilibrio nutricional en testudíneos son: metaplasia escamosa, hiperqueratosis del epitelio respiratorio y ocular, absceso aural, blefaroedema y descamación del caparazón. El diagnóstico se realiza principalmente por los signos clínicos, la historia alimentar y la capacidad de respuesta al tratamiento. El tratamiento es la aplicación de altas dosis de vitamina A, junto con el manejo nutricional adecuado. Este reporte describe el caso de una tortuga Trachemys dorbignyi de 23 años de edad, atendida en la Clínica Veterinaria Refugio Silvestre en Goiania, con blefaroedema, descamación del caparazón , ataxia, incoordinación motora, letargo, dificultad de locomoción. Después de todo el protocolo terapéutico realizado, el animal no respondió al tratamiento y falleció después de 11 días de hospitalización. Este caso tiene como objetivo mostrar la importancia de la planeación nutricional y ambiental en la calidad de vida de las mascotas silvestres y exóticas.

Palabras clave: fauna silvestre, hipovitaminosis, alimentación reptil

\section{Introdução}

A hipovitaminose A é uma afecção comum em cágados de água doce, causada pelos níveis insuficientes de vitamina A em seu organismo (Cubas et al., 2014). A vitamina A tem diversas funções, sendo uma delas a manutenção do tecido epitelial de todo organismo (Schilliger, 2010). Sua carência altera o metabolismo das células epiteliais, causando metaplasia escamosa e hiperqueratose dos epitélios, principalmente respiratório e ocular (Cubas et al., 2014). A classe dos répteis parece não absorver adequadamente o betacaroteno, um carotenoide encontrado em vegetais e considerado o mais importante precursor da vitamina A. Uma fonte dietética de precursores de vitamina A é necessária a todos os vertebrados, para suprimento dessa carência nutricional. A confirmação do diagnóstico é feita através dos sinais clínicos, histórico alimentar e responsividade ao tratamento com doses da vitamina A (Mans and Braun, 2014).

\section{Material e Métodos}

Um tigre d'água (Trachemys dorbignyi) atendido no dia 29 de setembro de 2015, 23 anos, fêmea, pesando $1,054 \mathrm{~kg}$. O animal alimentava-se de fígado de frango (a cada três dias), frutas, alface e alimento a base de Gammarus tacustris $\left(\right.$ Alcon $\left.{ }^{\circledR}\right)$. Durante a consulta, o animal apresentava letargia, apatia, incoordenação motora, dificuldade de locomoção, descamação da carapaça, além disso, ele não estava defecando, permanecia boa parte do dia em ambiente terrestre e somente uma hora do dia em ambiente aquático. Ao exame físico o paciente apresentou mucosas normocoradas, estado de consciência em estupor, desidratação, blefaroedema e dispneia.

Pelos sinais clínicos apresentados, o animal foi diagnosticado com hipovitaminose A, pneumopatia e/ou impactação. Para confirmação das suspeitas clínicas diagnósticadas foram solicitados como exames complementares radiografias nas projeções dorsocaudal e craniocaudal da cavidade celomática pela suspeita de presença de corpos estranhos e/ou impactação no trato gastrointestinal, além da suspeita de pneumonia.

No laudo, os campos pulmonares apresentavam maior radiopacidade e o segmento intestinal direito estava parcialmente preenchido por gás. Foram prescritos para o tratamento, cetoprofeno $2,0 \mathrm{mg} / \mathrm{kg}$, IM, uma vez ao dia (SID), durante cinco dias; complexo de vitaminas Bionew, 0,3 ml $/ \mathrm{kg}$, IM, SID, durante cinco dias; 
enrofloxacina, $15 \mathrm{mg} / \mathrm{kg}$, IM, SID, durante quatro dias, vitamina A, $5.000 \mathrm{UI} / \mathrm{kg}$ ou $0,05 \mathrm{ml}$, IM, SID, a cada sete dias. Foi feito enema com $20 \mathrm{~mL}$ de óleo mineral $(20 \mathrm{~mL} / \mathrm{kg}$ do animal $)$. A nebulização no animal foi realizada com $10 \mathrm{~mL}$ de soro fisiológico e $1,0 \mathrm{~mL}$ de gentamicina, via inalatória, BID. Como tratamento de suporte foi instituída fluidoterapia aquecida a temperatura ambiente na dose de $25 \mathrm{~mL}$ (20-25 mL/kg/dia) de ringer lactato devido a desidratação intensa do animal. Após a administração das medicações, o paciente foi aquecido em ambiente com isolamento aproximadamente $30^{\circ} \mathrm{C}$ por 30 a 40 minutos para termorregular e metabolizar as medicações.

\section{Resultados e Discussão}

O diagnóstico de hipovitaminose A com apresentação de blefaroedema (Figura 1A e 1B) é realizado por meio dos sinais clínicos (Figura 1C), histórico alimentar e resposta ao tratamento (2.000-5.000 UI), sendo o principal diagnóstico diferencial a blefarite, que é causada por irritações, corpos estranhos, infecções bacterianas e/ou parasitárias (Schilliger, 2010). A confirmação do diagnóstico da hipovitaminose A foi possível mediante aos sinais clínicos característicos apresentados pelo paciente, bem como por seu histórico alimentar inadequado.

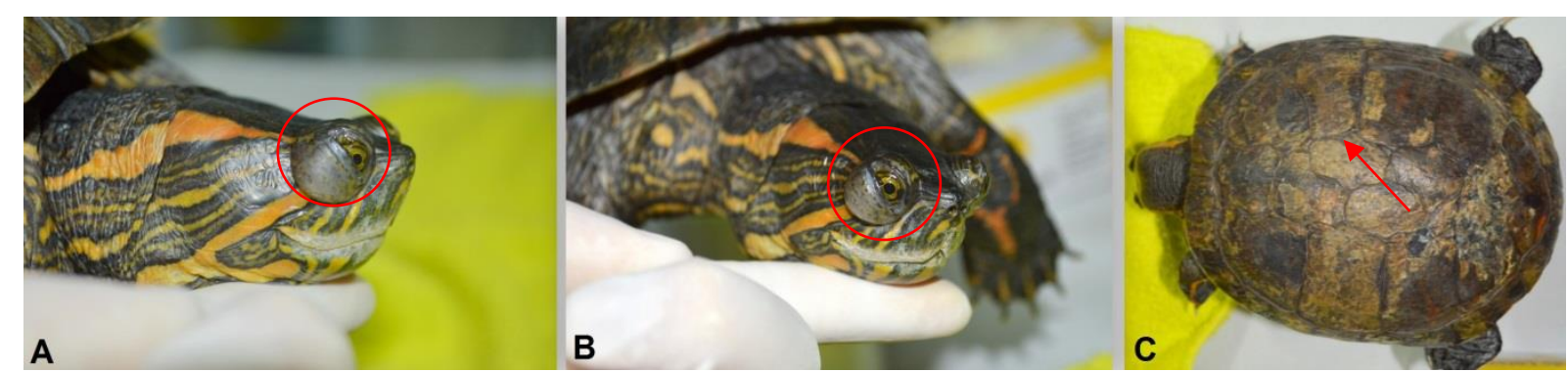

Figura 1. Sinais clínicos do tigre d'água (Trachemys dorbignyi). A - vista lateral do blefaroedema. B - vista oblíqua do blefaroedema. C - descamação de carapaça

O protocolo terapêutico para hipovitaminose $\mathrm{A}$ consiste na aplicação intramuscular (IM) de doses elevadas de vitamina A $(5.000 \mathrm{UI} / \mathrm{kg})$, dependendo da gravidade dos sinais clínicos demonstrados pelo animal (Mans and Braun, 2014). Preconiza-se o uso de antibioticoterapia, de acordo com os sinais clínicos e no caso de achados radiográficos indicativos de comprometimento pulmonar. A nebulização também é recomendada com objetivo de eliminar secreções do trato respiratório (Cubas et al., 2014). O protocolo de tratamento instituído foi o indicado pela literatura, porém, o paciente não apresentou melhora. Além disso, o manejo ambiental do animal era inadequado - permanecia mais tempo em ambiente terrestre, o que está em desacordo com seu habitat semiaquático, induzindo o desenvolvimento de quadro de estresse crônico.

A prevenção para a hipovitaminose A consiste no fornecimento de alimentos ricos em betacaroteno, como vegetais folhosos verdeescuros, frutas amarelas e alaranjadas (espinafre, brócolis, cenoura, pimentão-verde e abóbora) (Divers and Mader, 2005). Na dieta dos testudíneos aquáticos, utilizam-se, ainda, peixes, algas marinhas, neonatos de camundongos e, preferencialmente, dietas comerciais balanceadas (Cubas et al., 2014).
O prognóstico para este caso foi, portanto, de reservado a desfavorável, em função do quadro clínico que o animal apresentava e da não responsividade ao protocolo de tratamento instituído. O óbito do animal ocorreu no dia 09 de outubro de 2015, 11 dias após atendimento.

Pode-se concluir que, o desconhecimento de alguns proprietários sobre os manejos nutricional, ambiental e sanitário de seus pets silvestres e exóticos levam o surgimento da hipovitaminose A nesses animais. Essa conscientização sobre os manejos dos pets deve ser realizada pelos médicos veterinários de animais silvestres, que além de possuir conhecimentos básicos veterinários, também precisam ter conhecimentos biológicos da espécie atendida, visando melhoria da qualidade de vida do animal.

\section{Referências Bibliográficas}

Cubas, Z. S., Silva, J. C. R. \& Dias, J. L. C. 2014. Tratado de animais selvagens-medicina veterinária. Editora Roca.

Divers, S. J. \& Mader, D. R. 2005. Reptile medicine and surgery. Elsevier Health Sciences. 
Mans, C. \& Braun, J. 2014. Update on common nutritional disorders of captive reptiles. Veterinary Clinics of North America: Exotic Animal Practice, 17, 369-395.

Schilliger, L. 2010. Six affections oculaires à connaître chez les reptiles. Pratique, 45, 140145 .
Article History:

Received 18 January 2017

Accepted 22 February 2017

Available on line 28 March 2017

License information: This is an open-access article distributed under the terms of the Creative Commons Attribution License 4.0, which permits unrestricted use, distribution, and reproduction in any medium, provided the original work is properly cited. 